\title{
Annular-Geometry Ion Engine: Concept, Development Status, and Preliminary Performance
}

\author{
Michael J. Patterson ${ }^{*}$, Daniel Herman ${ }^{\dagger}$, Rohit Shastry ${ }^{\ddagger}$, and Jonathan Van Noord ${ }^{\S}$ \\ NASA Glenn Research Center, Cleveland, Ohio, 44135 \\ and \\ John E. Foster** \\ University of Michigan, Ann Arbor, Michigan, 48109
}

\begin{abstract}
This publication discusses the concept, projected capabilities, technology development plan, and preliminary performance data obtained for an Annular-Geometry Ion Engine (AGI-Engine). The AGI-Engine is the basis for a new class of Next-Generation Electric Propulsion Thrusters under investigation at NASA Glenn Research Center. The AGI-Engine holds the promise of achieving substantial increases in input power $(>10 \mathrm{X})$ and power density (2-3X) relative to conventional ion thrusters at specific impulse values of interest for near-term mission applications.
\end{abstract}

$\begin{array}{ll}\text { AGI-Engine } & =\text { Annular-Geometry Ion Engine } \\ \text { DMH-Engine } & =\text { Dual-Mode Hybrid Engine } \\ \text { EP } & =\text { Electric Propulsion } \\ \text { GRC } & =\text { Glenn Research Center } \\ \text { HET } & =\text { Hall-Effect Thruster } \\ \text { Isp } & =\text { Specific Impulse, seconds } \\ \text { MAGI-Engine } & =\text { Multi-ring Annular-Geometry Ion Engine } \\ \text { NCA } & =\text { Neutralizer Cathode Assembly } \\ \text { NGEPT } & =\text { Next-Generation Electric Propulsion Thruster } \\ \text { PG } & =\text { Pyrolytic Graphite }\end{array}$

\section{Introduction}

The Annular-Geometry Ion Engine (AGI-Engine) is the design core for a new class of electric propulsion (EP) thrusters, referred to as the Next-Generation Electric Propulsion Thruster (NGEPT). ${ }^{1,2}$ The NGEPT approach holds the potential to quickly develop high-power $(10 \mathrm{~kW}$ to $>300 \mathrm{~kW})$, high performance electric propulsion technology options which could then be rapidly transitioned-to-flight. It does so by providing a pathway to extend the application space of electrostatic ion thruster technology to high power operation $(>10 \mathrm{~kW})$ at modest levels of specific impulse (Isp) $(\leq 5,000 \mathrm{~s})$. In so doing this approach can then leverage the $>100,000$ s of hours of applicable life testing and relevant flight experience gained to date using this technology, to meet the ever more demanding needs for high power EP performance and lifetime at the specific impulses of interest for near-term mission applications.

The NGEPT objective of rapid development is approached using a thruster concept which: (1) is based upon well-understood physics relative to performance and life characteristics; (2) represents an incremental change to State-of-Art (SOA) technology - a 'low risk/high payoff' approach; and (3) has the potential to be responsive to the needs of a very large customer base (NASA, non-NASA government, and commercial sectors) using a reconfigurable design which may allow for amortization of the development and flight production costs over multiple users. The latter aspect is of particular importance to eliminate the remaining two key barriers to the widespread implementation of EP; the large costs associated with EP systems and the high perceived risk.

The key feature of the NGEPT is the AGI-Engine. Early positive test results achieved with a breadboard AGI-discharge chamber were recently published. ${ }^{2}$ These data, along with mission analyses results which indicate that

\footnotetext{
* Senior Technologist, Power and In-Space Propulsion Division, 21000 Brookpark Road/MS 301-3, Member AIAA.

Aerospace Engineer, Propulsion and Propellants Branch, 21000 Brookpark Road/MS 16-1, Member AIAA.

* Aerospace Engineer, Propulsion and Propellants Branch, 21000 Brookpark Road/MS 301-3, Member AIAA.

$\S$ Aerospace Engineer, Propulsion and Propellants Branch, 21000 Brookpark Road/MS 16-1, Member AIAA.

** Associate Professor, Nuclear Engineering and Radiological Sciences Department, 2355 Bonisteel Blvd., Member AIAA.

${ }^{\dagger}$ All concepts disclosed in the publication are Patent-Pending and are filed under both U.S. and International Patent Applications. Assignee: United State Government.
} 
the AGI-Engine and NGEPT capabilities compare favorably against other high power EP options ${ }^{3}$ were considerations in the selection of this concept for further agency investment and investigation. The breadboard AGI-discharge chamber was subsequently modified for operation with beam extraction and preliminary performance data for this AGI-Engine was obtained and is presented herein. Also discussed are the concept, its potential capabilities, and a technology development plan for its maturation.

\section{A. Design}

\section{Concept Discussion}

The AGI-Engine concept consists of an annular discharge chamber, with a set of annular ion optics, potentially configured with a centrally-mounted neutralizer cathode assembly (NCA). This concept is illustrated in Figure 1, a cross-section schematic and a photo of the breadboard discharge chamber hardware. Figure 2 shows both the breadboard discharge chamber in operation with simulated-beam extraction ${ }^{\dagger}$, and the breadboard AGIE-Engine operating with beam extraction.

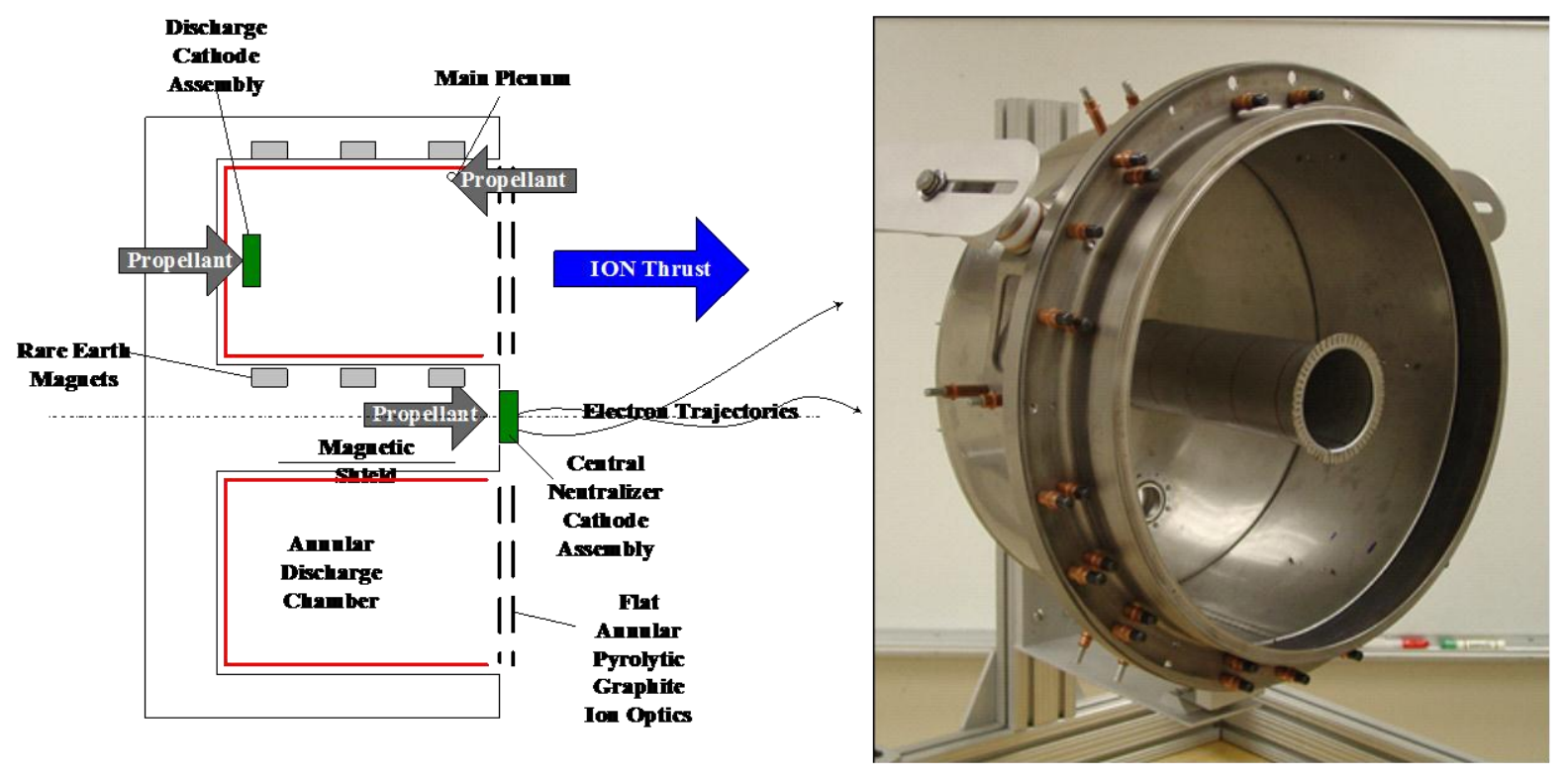

Figure 1 AGI-Engine: conceptual schematic (left); photo of breadboard discharge (right)
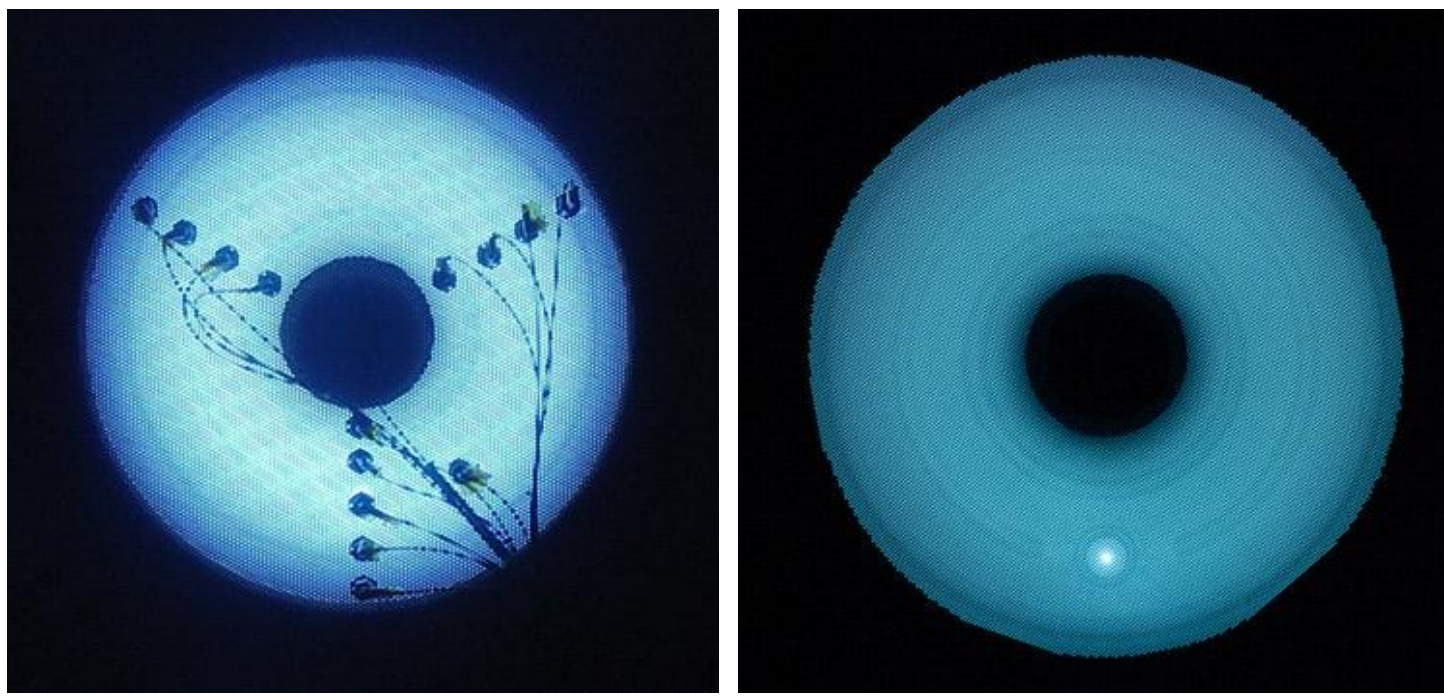

Figure 2 AGI-Engine: photo of discharge operation with simulated beam-extraction (note downstream grid plate with embedded current probes, left); photo of engine operation with beam extraction (right)

¥¥ This refers to ion thruster operation without beam extraction, as described in a later section 


\section{B. Attributes}

The potential advantages of the AGI-Engine, as compared to ion thrusters of conventional configuration (cylindrical discharge with spherically-domed circular ion optics) are many. ${ }^{1}$ The concept attributes and corresponding technical descriptions for the AGI-Engine are listed in Table 1.

The primary advantage of the concept is that it provides a means of extending the power range (scalability) of ion thruster technology to $>>10 \mathrm{~kW}$ at modest levels of specific impulse $(<5,000$ seconds). This is because the annular ion optics enables very-large beam areas while limiting both the span and span-to-gap of the electrodes for the high-perveance designs needed for this power and Isp range. Other potential advantages of the concept include the ability to operate at much higher power and thrust densities than SOA thrusters due to increased anode area, as well as improved efficiencies, longer lifetimes, etc.

Table 1 Annular-Geometry Ion-Engine Concept Attributes and Descriptions

\begin{tabular}{|c|c|}
\hline Concept Attribute & anical Description \\
\hline $\begin{array}{l}\text { Scalability to High } \\
\text { Power } \rightarrow \text { Increase } \\
\text { Input Power Levels } \\
\text { by }>10 \mathrm{X} \text { over SOA }\end{array}$ & $\begin{array}{l}\text { The annular-geometry ion optics should allow for scaling of ion thrusters to very high power }(>100 \text { 's of } \\
\mathrm{kW}) \text { at specific impulse values of interest }(\leq 5,000 \mathrm{sec}) \text { by permitting very-large beam areas with } \\
\text { relatively small electrode spans, and relatively small span-to-gap ratios } \\
\text { This circumvents the manufacturing, and the mechanical and thermal stability issues inherent with } \\
\text { attempting to ever-increase the beam area via increasing the diameter of spherically-domed ion optics } \\
\text { used on conventional cylindrical ion thrusters; typically limited to } \leq 50 \mathrm{~cm} \text { diameter } \\
\text { The AGI-Engine approach allows for a dramatic reduction in optics span, and span-to-gap ratio for a } \\
\text { given beam area over ion optics of conventional design: typically a } 4-6 \mathrm{X} \text { reduction in span and } \\
\text { span-to-gap ratios. }\end{array}$ \\
\hline $\begin{array}{l}\text { Operation at Higher } \\
\text { Power and Thrust } \\
\text { Densities } \rightarrow \text { up to } \\
3 \mathrm{X} \text { over SOA }\end{array}$ & $\begin{array}{l}\text { The annular-shaped discharge chamber of the AGI-Engine increases the effective anode-surface area } \\
\text { for electron-collection as compared to a conventional cylindrically-shaped ion thruster of equivalent beam } \\
\text { area. This should allow the ion thruster component of the AGI-Engine to operate utilizing the } \\
\text { full-perveance capability of the ion optics, and not have its maximum input power level limited by the } \\
\text { available anode surface area. } \\
\text { This increase in anode surface area should allow the AGI-Engine to operate at higher discharge currents } \\
\text { and therefore potentially higher beam currents and input power levels than a SOA ion thruster of } \\
\text { equivalent beam area for a given specific impulse: typically a 2-3X increase in power density. }{ }^{1}\end{array}$ \\
\hline $\begin{array}{l}\text { Improved } \\
\text { Efficiencies over } \\
\quad \text { SOA }\end{array}$ & $\begin{array}{l}\text { Annular-geometry ion optics of small span should have a sufficiently-high first mode natural frequency to } \\
\text { allow for the application of flat electrodes. Flat electrodes will inherently yield improved T/P-ratios and } \\
\text { efficiencies as compared to SOA ion thrusters by eliminating the off-axis beam vectoring associated with } \\
\text { spherically-domed ion optics electrodes used on cylindrical thrusters. For example, the application of } \\
\text { flat electrodes on the NEXT ion thruster would yield a } \sim 3-4 \text { percentage point increase in efficiency across } \\
\text { its entire specific impulse throttling range. }\end{array}$ \\
\hline $\begin{array}{l}\text { Practical } \\
\text { Implementation of } \\
\text { Carbon } \rightarrow \\
\text { Improved Lifetime } \\
\quad \text { over SOA }\end{array}$ & $\begin{array}{l}\text { The use of small span and flat electrode geometry for the AGI-Engine ion optics should allow for the } \\
\text { practical implementation of carbon for larger areas, in the form of pyrolytic graphite (PG) panels, and } \\
\text { thereby eliminate the thruster primary-failure mode. } \\
\text { Application of carbon electrodes for ion thrusters is advantageous due to its nearly order-of-magnitude } \\
\text { improvement in life capability associated with its reduced sputter-yield relative to conventional refractory } \\
\text { metals. The implementation of carbon - in both carbon-carbon and PG form - for conventional ion } \\
\text { thruster electrodes have to date been inhibited by manufacturing limitations. } \\
\text { Because of the relatively-simple physical design of the electrodes for an AGI-Engine, these } \\
\text { manufacturing limitations are circumvented - thereby allowing the practical implementation of carbon } \\
\text { and hence the life time enhancements of this material. }\end{array}$ \\
\hline $\begin{array}{l}\text { Implementation of } \\
\text { High-Perveance Ion } \\
\text { Optics Designs }\end{array}$ & $\begin{array}{l}\text { Because of reduced span and space-to-gap requirements, and flat electrode configuration, } \\
\text { higher-perveance designs (thinner electrodes, higher open-area-fraction electrodes, and/or reduced } \\
\text { inter-electrode gaps) could potentially be enabled with annular-geometry flat ion optics, thereby allowing } \\
\text { for operation at higher thrust densities. }\end{array}$ \\
\hline Packaging & $\begin{array}{l}\text { The annular discharge chamber design of the AGI-Engine provides for efficient packaging by providing } \\
\text { a central position for mounting the NCA within the annulus, thereby reducing the outer profile of the } \\
\text { engine and eliminating the need for a cantilevered-outboard NCA employed on conventional ion } \\
\text { thrusters. } \\
\text { This annular design also allows for the potential to incorporate multiple annular discharges packaged } \\
\text { into concentric rings, or for integration of other EP devices or chemical thrusters within the annulus. } \\
\text { This would also allow for a shared gimbal platform. }\end{array}$ \\
\hline
\end{tabular}

\section{Configurations and Capabilities}

The AGI-Engine concept could be implemented in a variety of physical manifestations, depending upon the intended application, as illustrated in Figure 3. These potential manifestations, or NGEPT configurations, include the following:

1. Stand-alone Ion Thruster; AGI-Engine. The concept (reference Fig. 3a) could be implemented simply as an ion thruster, an AGI-Engine, providing the aforementioned performance attributes.

2. Multi-ring Annular-Geometry Ion Engine; MAGI-Engine. Multiple concentric AGI-Engine rings could be integrated into a nested-configuration, as illustrated in Figure 3b, a 4-ring configuration, with each ring operating 
individual or in combination. This configuration could thereby increase the effective power throttling range of the engine to $>100: 1$, with each ring providing individually or collectively the aforementioned performance attributes.

3. Dual-Mode Hybrid-Engine; DMH-Engine. The AGI-Engine could be integrated with another EP thruster technology - e.g. mounted concentrically around the exterior of a Hall Effect Thruster (HET) as illustrated in Figure $3 \mathrm{c}$ - to form a single integrated assembly using common propulsion elements (gimbal platform, power electronics, and feed system). This was the original concept for the NGEPT, conceived as a means to achieve the combined performance characteristics of both EP thruster technologies into a single integrated assembly operating over the broadest possible Isp range and doing so matching or exceeding the efficiency of multiple SOA thrusters at high power. ${ }^{1}$ Another potential DMH-Engine configuration is an AGI-Engine/Chemical thruster hybrid. Both the EP/EP and EP/chemical thruster hybrids provide the potential for 'dual-mode' operation; combining high-Isp and high-thrust capabilities on a common platform. For the EP/EP hybrid, this could have two manifestations: a 'matched-mode' where both the AGI-Engine and alternate EP thruster technology are sized to operate at comparable power levels - each providing primary propulsion functions (depicted in Fig. 3c); and a 'mixed-mode' where the AGI-Engine is a much lower power device, providing an on-station (auxiliary) high-Isp capability to complement a high power EP thruster used for primary propulsion. ${ }^{1}$ In the latter configuration the AGI-Engine would constitute a very-narrow span annular ring, concentrically mounted around another EP thruster technology (a large HET, for example).

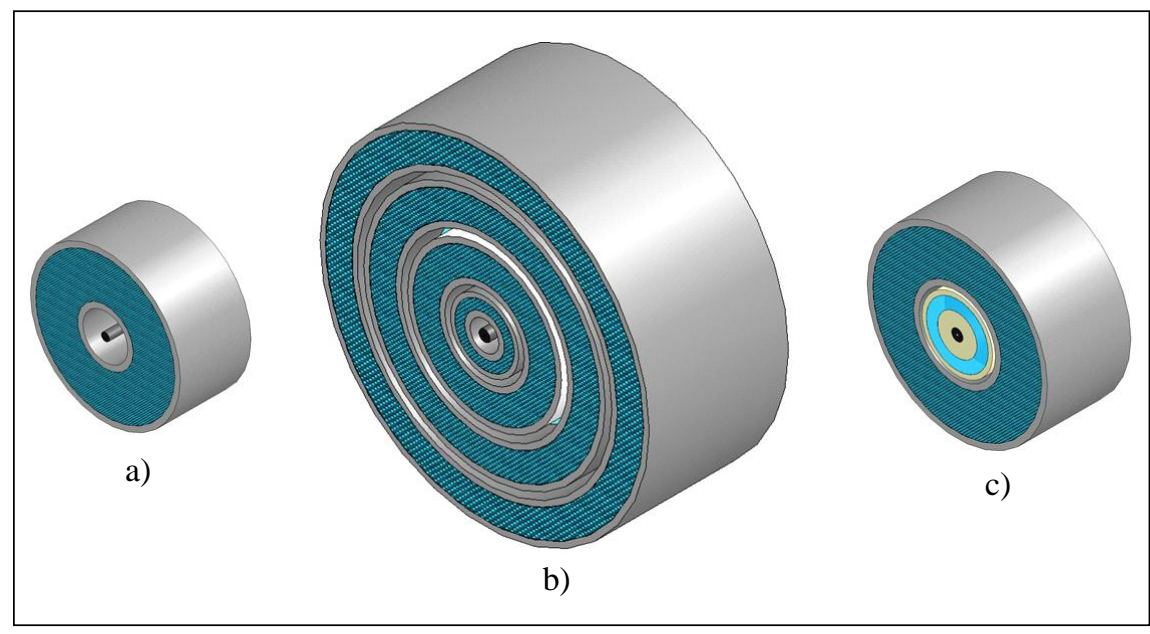

\section{Figure 3 NGEPT Configurations: AGI-Engine (a); MAGI-Engine (b); DMH-Engine (AGI-Engine/HET} Hybrid) (c)

Figures 4-6 provide estimated performance characteristics for 3 example cases of the NGEPT configurations depicted in Figure 3. In Fig. 4 estimated maximum input power vs. Isp is plotted for a modestly-sized AGI-Engine (depicted in Fig. 3a). The assumed AGI-Engine has an (annular) interior and exterior beam diameter of $26 \mathrm{~cm}$ and 65 $\mathrm{cm}$ respectively, yielding a total beam area of approximately $0.24 \mathrm{~m}^{2}$ with a maximum electrode span of $17 \mathrm{~cm}$. Also plotted is the power and specific impulse range for NASA's $40 \mathrm{~cm}$ diameter NEXT ion thruster for comparison. ${ }^{4}$ As indicated in Fig. 4 input power levels exceeding $30 \mathrm{~kW}$ should be feasible with this AGI-Engine configuration. Over the entire range of specific impulse (from about 1,700-4,500 seconds) this AGI-Engine configuration should be able to operate at input power levels many factors higher than the SOA NEXT thruster. Thrust levels exceed 1 Newton for Isp values above about 4,000 seconds.

Figure 5 plots estimated maximum input power vs. Isp for each of the 4 rings of a MAGI-Engine, as well as the total input power into the engine assuming the simultaneous operation of all 4 rings. A constant span of $17 \mathrm{~cm}$ was assumed for all rings, with the outer-most ring having an outside diameter of approximately $1.5 \mathrm{~m}$. As noted, with the simultaneous operation of all rings, input power levels exceeding $0.10 \mathrm{MW}$ could be processed above about 1,800 seconds Isp, and > 0.30 MW processed above about 4,000 seconds Isp. Over the approximately 1,700-4,500 Isp range indicated the total thrust produced by the 4-ring MAGI-Engine would range from about $4.7-12.4$ Newtons.

The potential performance characteristics of a DMH-Engine - in this example case a hybrid created by combining an AGI-Engine with Aerojet's HPPS Hall Effect thruster ${ }^{5}$ integrated into the annulus of the ion channel - is shown in Fig. 6. This configuration is depicted in Fig. 3c, and assumes an AGI-Engine interior and exterior beam diameter of $39 \mathrm{~cm}$ and $75 \mathrm{~cm}$ respectively, yielding a total beam area of approximately $0.28 \mathrm{~m}^{2}$ and maximum electrode span of $15.5 \mathrm{~cm}$. Figure 6 is a plot of the anticipated thrust-to-power ratio vs. specific impulse for this DMH-Engine. Also plotted are several other SOA and high-power EP thrusters under development including the BPT-4000 thruster ${ }^{6}$, the VASIMR engine ${ }^{7}$, the Pulsed Inductive Thruster (or PIT) ${ }^{8}$, Aerojet's HPPS Hall Thruster (as a stand-alone), NASA's NEXT ion thruster, and a Lithium Magneto-Plasma Dynamic (or MPD) thruster ${ }^{9}$. Also plotted is a theoretical EP 
thruster having a constant efficiency of $70 \%$ over the indicated range of specific impulse. As noted in Fig. 6 the estimated performance of the DMH-Engine exceeds the performance of all other EP technology options shown, yielding a higher $\mathrm{T} / \mathrm{P}$ ratio over the entire range of specific impulse from 1,500-4,500 seconds.

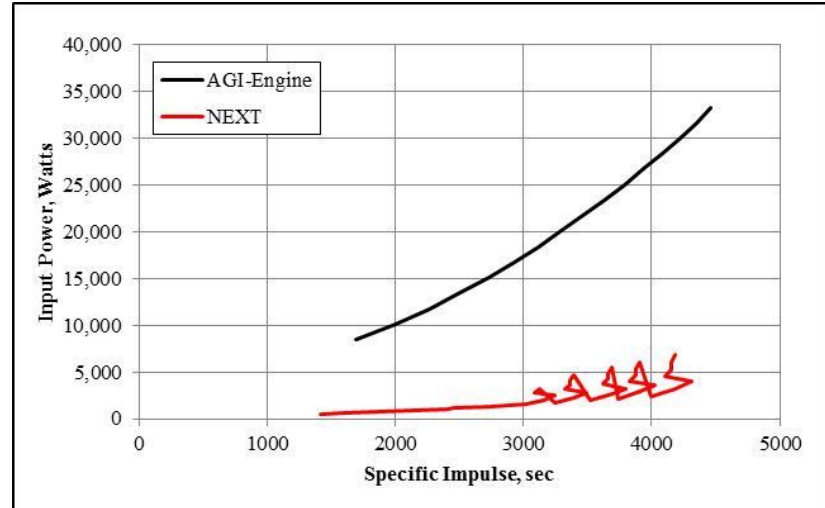

Figure 4 AGI-Engine estimated Input Power vs. Specific Impulse. Also plotted are data for the NEXT thruster.

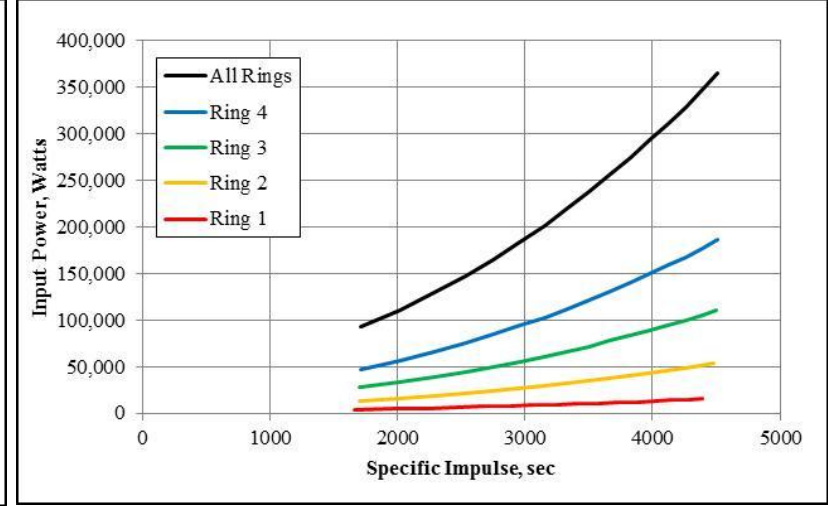

Figure 5 4-Ring MAGI-Engine estimated Input Power vs. Specific Impulse.

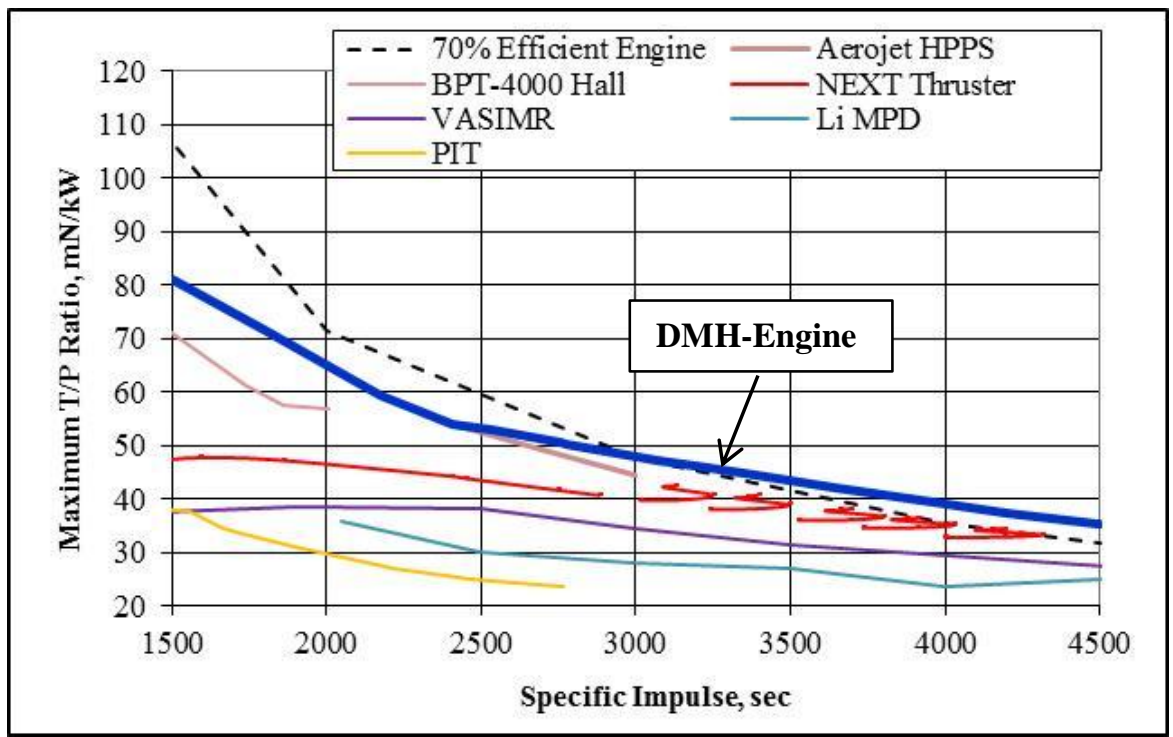

Figure 6 Thrust-to-Power Ratios vs. Specific Impulse for SOA EP Thrusters; DMH-Engine is an AGI-Engine/HPPS HET Hybrid

Figure 7 provides a summary chart of the various configurations of the NGEPT, all of which are derived from the AGI-Engine concept. Each configuration is illustrated, with application, and potential capabilities identified.

\section{Technology Development Plan}

The primary attribute of the AGI-Engine is its potential to enable scaling of ion thruster technology to high power, at moderate levels of specific impulse by providing an engineering approach to the manufacture of high-perveance large-area ion optics. Other potential attributes of the concept - higher thrust and power densities because the design may support higher discharge and beam currents, higher efficiencies and longer life times than SOA thrusters via incorporation of flat-electrodes using carbon - while highly-advantageous if achievable, are not critical to the value of the concept as a high-power technology option.

Table 2 lists the development tasks necessary to mature the AGI-Engine to its full potential. Those tasks associated with demonstrating high power operation and scalability of the concept, \#1-\#6, are identified as critical requirements. These include: demonstrating the ability to generate a stable, uniform plasma discharge, with relatively-low discharges losses; demonstrating uniform beam current densities under beam extraction; and demonstrating feasibility of the annular ion optics at subscale, and scalability of both the annular discharge and ion optics to large size (> $36 \mathrm{~cm}$ beam diameters). 


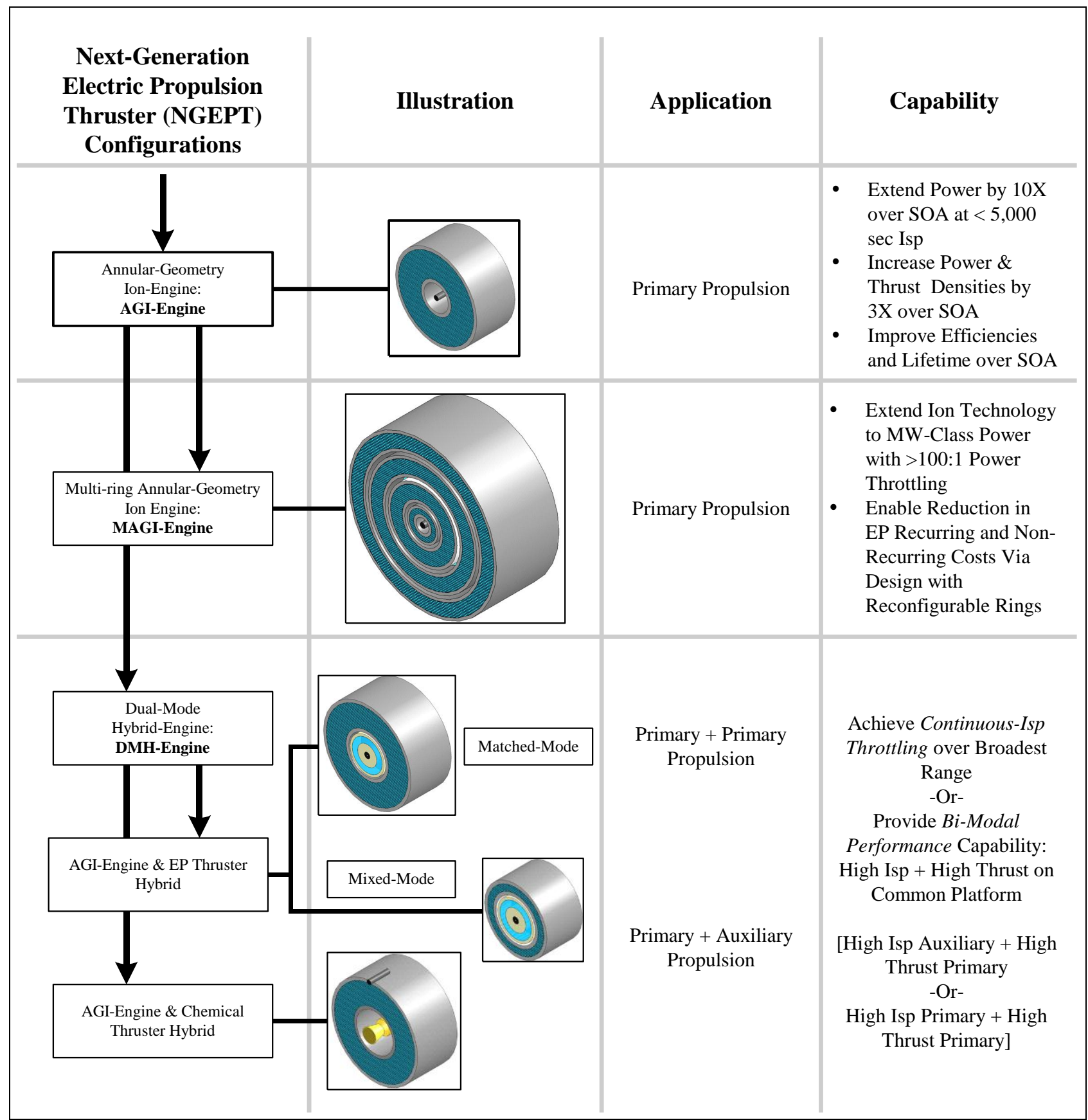

Figure 7 AGI-Engine Based NGEPT Configurations, Applications, and Capabilities

Development tasks \#7-\#10 listed in Table 2 are those tasks important to demonstrating the full potential of the AGI-Engine concept. These include: demonstrating operation at higher power and thrust densities than SOA technologies, via operation at higher discharge and beam currents (\#7 and \#8); demonstrating improved life time over SOA by successful demonstration of annular ion optics manufactured from carbon (\#9); and demonstrating improved efficiencies over SOA by successful demonstration of annular optics using flat electrodes. 
Table 2 AGI-Engine Development Tasks and Concept Requirements

\begin{tabular}{|l|c|}
\hline \multicolumn{1}{|c|}{ Development Task } & Critical Requirement? \\
\hline \#1. Demonstrate Stable Annular Discharge Operation & Yes \\
\hline \#2. Demonstrate Uniform Annular Plasma Densities & Yes \\
\hline \#3. Demonstrate Low (<400 W/A) Discharge Losses & Yes \\
\hline \#4. Demonstrate Uniform Beam Current Density & Yes \\
\hline \#5. Demonstrate Feasibility of Annular Ion Optics at Sub-Scale & Yes \\
\hline \#6. Demonstrate Scalability of Annular Discharge-and-Ion Optics & No; Highly Advantageous \\
\hline \#7. Demonstrate Higher Supportable Discharge Currents than SOA & No; Highly Advantageous \\
\hline \#8. Demonstrate Higher Beam Current Densities than SOA & No; Highly Advantageous \\
\hline \#9. Demonstrate Carbon-Based Annular Ion Optics & No; Advantageous \\
\hline \#10.Demonstrate Feasibility of Flat Annular Ion Optics &
\end{tabular}

\section{Development Status and Preliminary Performance}

\section{A. Breadboard AGI-Engine Hardware}

With the exception of prior work on domed metal annular electrodes, ${ }^{10,11}$ gridded ion engines with an annular geometry including annular discharge chamber have never been conceived. Fundamentally, there is nothing that precludes an annular geometry. However a major challenge is in achieving a discharge chamber magnetic-circuit design with discharge losses comparable to conventional cylindrical engines such as the NEXT thruster. Through 3-D electromagnetic simulations the University of Michigan and NASA GRC have developed magnetic circuit designs for the AGI-Engine concept that meets all the established design criteria for multi-pole ring cusp circuits. Most other aspects of the AGI-Engine are based on well-established elements of a conventional ion engine.

Using a combination of discharge components originally manufactured for an engineering model NEXT ion thruster and others fabricated specifically for the AGI-Engine, a subscale annular discharge chamber was constructed at NASA GRC. This breadboard AGI-Engine discharge, shown in Fig. 1 photograph (sans magnetic circuit, discharge cathode, and ion optics) has an $8 \mathrm{~cm}$ inside diameter and $42 \mathrm{~cm}$ outside diameter. A singular hollow cathode was installed in the breadboard discharge as an electron source at a radial position corresponding to the center of the annulus. The effective anode surface area for the breadboard AGI-Engine discharge is approximately $1.52 \mathrm{X}$ that of the NEXT thruster.

For discharge tests, a single perforated screen was placed on the downstream of the discharge chamber to simulate a set of ion optics. This downstream grid plate had an open area fraction equal to the neutral transparency of high perveance ion optics and was biased to cathode potential and electrically isolated from the (anode potential) discharge chamber. Embedded in the grid plate were a series of current probes at various positions to measure the azimuthal and radial variations in plasma density. Figure 2 shows operation of the discharge. The current probes are apparent in the downstream grid plate, and are positioned in radial lines along 3 azimuthal positions located at approximately 2-, 6-, and 10-O'clock. One of the current probes, the middle probe along the 6-O'clock radius, was positioned to be directly downstream of the discharge hollow cathode. The objectives of the discharge tests were to determine whether or not a stable discharge could be established, ascertain the degree of azimuthal and radial uniformity of the discharge, and estimate the electrical efficiency of the discharge under conditions simulating beam extraction.

For engine tests with beam extraction, the downstream grid plate was removed and a set of modified NEXT ion optics were installed. The modification to the NEXT ion optics involved installation of an $8 \mathrm{~cm}$ diameter patch on the upstream center of the screen electrode to simulate an annular beam configuration of $8 \mathrm{~cm}$ inner diameter and $36 \mathrm{~cm}$ outside diameter. A NEXT ion optics set was used in lieu of annular electrodes which were still under fabrication at the time of these tests. The effective beam area of the breadboard AGI-Engine is approximately 0.96X that of the NEXT thruster. The objectives of the beam extraction tests were to document the discharge electrical efficiencies and the beam current density profiles at a variety of beam currents and assess the operation of the ion optics and overall thruster performance.

The breadboard AGI-Engine discharge and beam extraction testing was conducted at NASA GRC's VF-7 space simulation facility (see Figure 8). VF-7 is a $3 \mathrm{~m}$ in diameter $4.6 \mathrm{~m}$ in length (thruster to target) cylindrical vacuum chamber equipped with 50.9 -m-diameter oil diffusion pumps. Pressure was monitored using an exposed hot-cathode ionization gauge mounted near the engine to provide an accurate measurement of the backpressure in the vicinity of the test article. Facility base pressures of $2.5 \times 10^{-8}$ Torr were routinely achieved. Research-grade xenon was supplied using commercially available mass flow controllers with an accuracy of $\pm 1 \%$ of the reading. Commercially available power supplies were used to operate the engine. Since this study was a preliminary test to compare the performance of the AGI-Engine to that of the NEXT thruster, the engine was operated using the standard NEXT 
throttle table as a guide throughout the majority of testing. Engine data was monitored and recorded throughout testing using calibrated digital multi-meters.

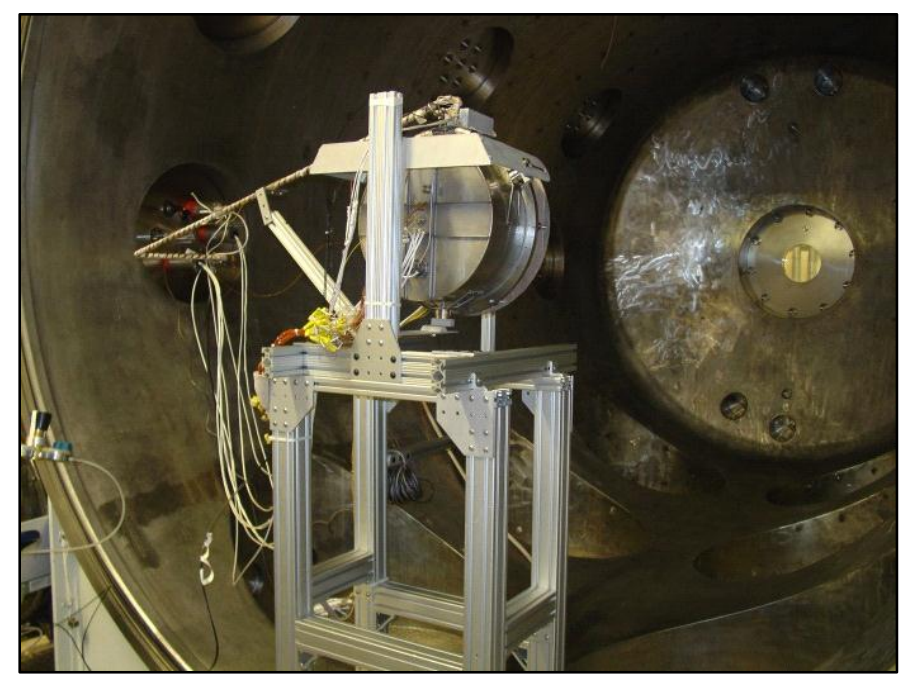

\section{Figure 8 Breadboard AGI-Engine Discharge Integrated into Vacuum Chamber at NASA GRC}

\section{B. Discharge Operation}

Discharge tests were performed over a range of discharge currents (approximately 10-48 Amperes) and discharge power levels (approx. 240-780 Watts) corresponding to conditions encompassing the entire throttling range of the NEXT ion thruster and beyond (above $7 \mathrm{~kW}$ equivalent engine input power). A series of comprehensive (discharge-only) tests were performed to document discharge stability, azimuthal and radial plasma uniformity, critical engine component temperatures, and estimate discharge losses under conditions simulating beam extraction.

The results of these tests were recently reported elsewhere ${ }^{2}$, but are summarized and expanded-upon here:

1. Stable operation of the annular discharge was demonstrated over the full range of discharge currents investigated, up to approximately 48 Amperes. Note that the maximum sustainable discharge current for the NEXT thruster is approximately 31 Amperes. The supportable discharge current for the AGI-Engine is therefore consistent with the $1.52 \mathrm{X}$ increase in effective anode area from the NEXT thruster to the breadboard AGI-Engine.

2. Highly-uniform azimuthal and radial discharge plasmas were observed at all conditions using this single hollow cathode design. For a given radial position, the current densities were typically within $10 \%$ of the mean at different azimuthal positions.

3. High ion currents were measured at the extraction plane by biasing the downstream grid plate at cathode potential; values consistent with high beam current/high power operation. Estimated discharge losses (when operated with beam extraction using annular ion optics) were determined from this data to be of the order of $200 \mathrm{~W} / \mathrm{A}$. High discharge electrical losses (identified as a major NGEPT technical risk) ${ }^{1}$ - due to the large ratio of anode area-to-discharge volume, or the asymmetry in the magnetic circuit associated with the discharge cathode placement, or both - could under some worst-case conditions preclude an increase in effective power density. It is noted however that even in the case of high discharge losses this concept should still permit scaling and operation at much higher powers levels - at specific impulse values less than 5,000 seconds - than achievable by SOA ion thrusters.

These tests were successful in:

1. Demonstration of development task \#1 - stable annular discharge operation;

2. Demonstration of development task \#2 - uniform annular plasma densities;

3. Partial demonstration of development task \#3 - the tests operating under conditions simulating beam extraction indicate that discharge losses $\leq 200 \mathrm{~W} / \mathrm{A}$ should be achievable with beam extraction, well below the maximum target value of $400 \mathrm{~W} / \mathrm{A}$; and

4. Partial demonstration of development task \#7 - demonstration of higher supportable discharge currents than SOA.

Based on the positive results achieved with the discharge tests modifications were made to the engine to accommodate high-voltage operation for performance characterization with ion beam extraction. Engine modifications included installation of: high voltage propellant isolators; modified NEXT ion optics (modified to simulate an annular configuration by covering the central $8 \mathrm{~cm}$ diameter portion of the electrodes); plasma ground screen; and a NCA positioned at 12-O'clock exterior to the discharge diameter.

\section{Performance with Beam Extraction}

Tests of the breadboard AGI-Engine were conducted to evaluate development tasks \#3 and \#4; demonstrate low discharge losses, and demonstrate uniform beam current densities. These tests would also provide an opportunity to 
document the operation of ion optics on the annular discharge, in advance of the completion of sub-scale annular ion optics, and document overall engine performance. Because the engine was built from NEXT thruster components the constraints of the discharge chamber diameter and optics size yield only a modest increase in anode area, and a reduction in the beam area relative to the NEXT thruster. Therefore the breadboard represents a subscale demonstrator with limited potential capability to operate at higher power and power densities than SOA thrusters.

The AGI-Engine performance and plume were documented over a subset of the standard NEXT ion thruster throttle level (TL) conditions, and at a number of new NEXT expanded throttle level (ETL) operating conditions. The NEXT TL operating conditions (in green) and ETL operating conditions (in yellow) are identified in Table 3, a matrix of beam currents and beam power supply voltages. [The throttle table consists of a number of discrete beam current and beam power supply voltages; the NEXT power processor unit of course has analog output and both the power processor and thruster can operate at any condition between the range of beam current and beam power supply voltages indicated.] Those conditions for which performance and plume data were obtained for the breadboard AGI-Engine are shown in bold in Table 3. The number of operating points were somewhat constrained by the poor original manufacturing quality of the ion optics (limiting the minimum beam voltage) and a high breakdown frequency at high beam voltage (attributable to sharp edges on the metal patch applied to occult the optics $8 \mathrm{~cm}$ diameter center), but these were more than adequate in number to document the discharge electrical efficiency and beam plume.

Table 3 NEXT Throttle Level (TL, green) and Extended Throttle Level (ETL, yellow) Conditions; AGI-Engine Characterization Conditions Identified in Bold

\begin{tabular}{|c|c|c|c|c|c|c|c|c|c|c|c|c|c|}
\hline \multirow{2}{*}{$\begin{array}{c}\text { Beam } \\
\text { Current, } \\
\text { A } \\
\end{array}$} & \multicolumn{13}{|c|}{ Beam Power Supply Voltage, V } \\
\hline & 1800 & 1567 & 1396 & 1179 & 1021 & 936 & 850 & 700 & 679 & 650 & 400 & 300 & 275 \\
\hline 3.52 & TL40 & TL39 & TL38 & TL37 & $\begin{array}{r}\text { ETL } \\
3.52 A \\
\end{array}$ & $\begin{array}{c}\text { ETL } \\
3.52 \mathrm{~B} \\
\end{array}$ & $\begin{array}{r}\text { ETL } \\
3.52 \mathrm{C} \\
\end{array}$ & $\begin{array}{r}\text { ETL } \\
3.52 \mathrm{D} \\
\end{array}$ & & & & & \\
\hline 3.10 & TL36 & TL35 & TL34 & TL33 & $\begin{array}{l}\text { ETL } \\
\text { 3.1A }\end{array}$ & $\begin{array}{l}\text { ETL } \\
\text { 3.1B } \\
\end{array}$ & $\begin{array}{l}\text { ETL } \\
3.1 \mathrm{C} \\
\end{array}$ & $\begin{array}{l}\text { ETL } \\
3.1 \mathrm{D} \\
\end{array}$ & $\begin{array}{l}\text { ETL } \\
3.1 \mathrm{E} \\
\end{array}$ & & & & \\
\hline 2.70 & TL32 & TL31 & TL30 & TL29 & TL28 & $\begin{array}{l}\text { ETL } \\
2.7 A \\
\end{array}$ & $\begin{array}{l}\text { ETL } \\
2.7 B \\
\end{array}$ & $\begin{array}{l}\text { ETL } \\
2.7 \mathrm{C} \\
\end{array}$ & $\begin{array}{l}\text { ETL } \\
2.7 \mathrm{D} \\
\end{array}$ & $\begin{array}{l}\text { ETL } \\
2.7 \mathrm{E} \\
\end{array}$ & & & \\
\hline 2.35 & TL27 & TL26 & TL25 & TL24 & TL23 & $\begin{array}{r}\text { ETL } \\
2.35 \mathrm{~A}\end{array}$ & $\begin{array}{c}\text { ETL } \\
2.35 B\end{array}$ & $\begin{array}{c}\text { ETL } \\
2.35 \mathrm{C}\end{array}$ & $\begin{array}{c}\text { ETL } \\
2.35 \mathrm{D}\end{array}$ & $\begin{array}{c}\text { ETL } \\
2.35 \mathrm{E}\end{array}$ & & & \\
\hline 2.00 & TL22 & TL21 & TL20 & TL19 & TL18 & $\begin{array}{l}\text { ETL } \\
2.0 A\end{array}$ & $\begin{array}{l}\text { ETL } \\
2.0 B\end{array}$ & $\begin{array}{l}\text { ETL } \\
2.0 \mathrm{C}\end{array}$ & $\begin{array}{l}\text { ETL } \\
2.0 D\end{array}$ & $\begin{array}{l}\text { ETL } \\
2.0 \mathrm{E}\end{array}$ & & & \\
\hline 1.60 & TL17 & TL16 & TL15 & TL14 & TL13 & $\begin{array}{l}\text { ETL } \\
1.6 A \\
\end{array}$ & $\begin{array}{l}\text { ETL } \\
1.6 B \\
\end{array}$ & $\begin{array}{l}\text { ETL } \\
1.6 \mathrm{C} \\
\end{array}$ & $\begin{array}{l}\text { ETL } \\
1.6 D \\
\end{array}$ & $\begin{array}{l}\text { ETL } \\
1.6 \mathrm{E} \\
\end{array}$ & $\begin{array}{l}\text { ETL } \\
1.6 \mathrm{~F} \\
\end{array}$ & & \\
\hline 1.20 & TL12 & TL11 & TL10 & TL09 & TL08 & TL07 & TL06 & & TL05 & TL04 & TL03 & TL02 & \\
\hline 1.00 & & & & & & & & & & & & & TL01 \\
\hline
\end{tabular}

The performance of the breadboard AGI-Engine discharge chamber is shown in in Fig. 9, a plot of discharge losses (in Watts per beam Ampere) vs. beam current (in Amperes). Plotted in Fig. 9 are both data obtained with beam

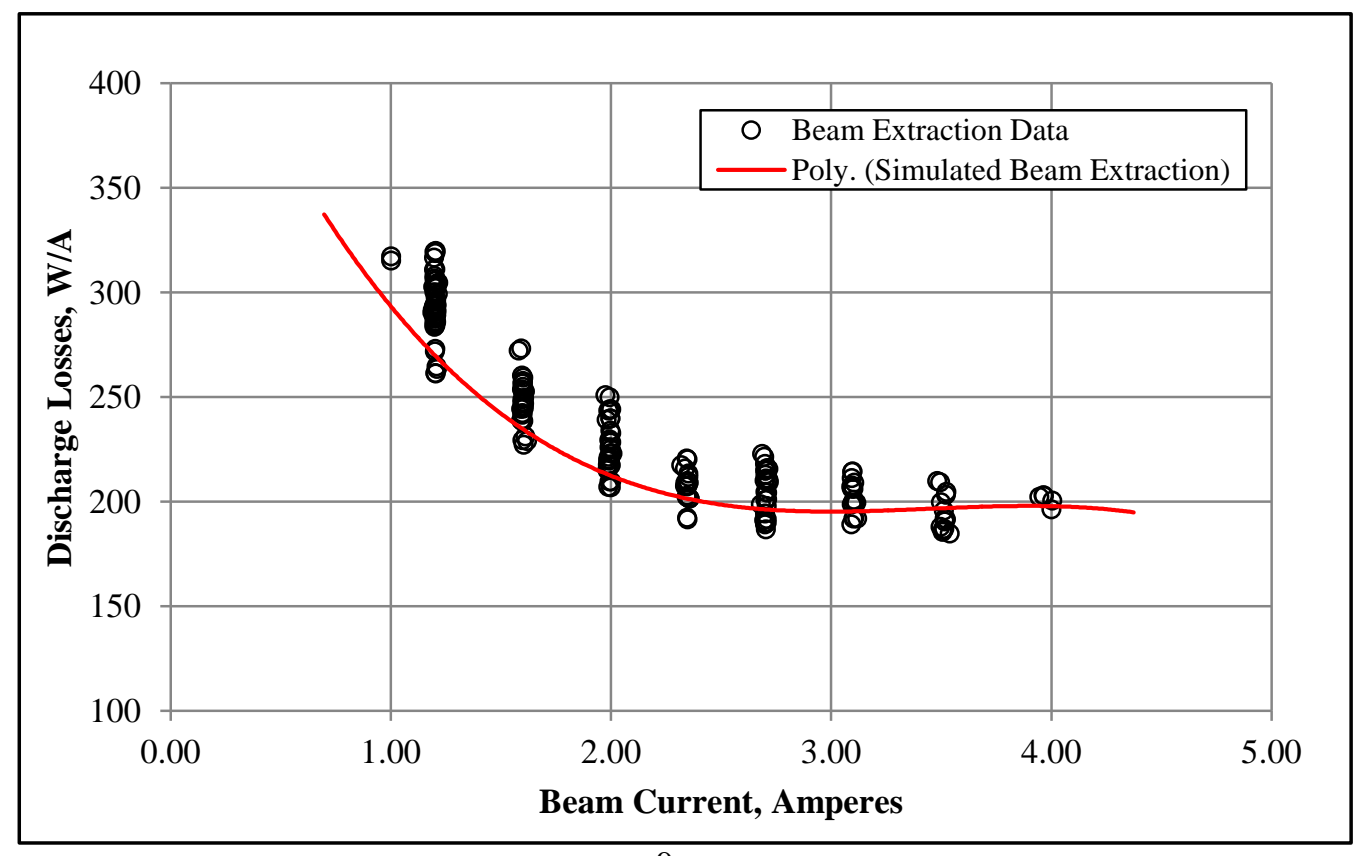

Figure 9 Breadboard AGI-Engine Discharge Losses vs. Beam Current 
extraction (for the conditions identified in Table 3), and a polynomial curve fit of data obtained with discharge-only operation (simulated beam extraction) reported earlier. ${ }^{2}$ Two things are of note in Fig. 9. Firstly, the discharge losses measured with beam extraction compare favorably to the estimates obtained initially from discharge-only operation using the methodology described in Ref. 12. ${ }^{\S}$ [The vertical striation in discharge losses for a given beam current correspond to variations in total voltage associated with the various throttle levels, with the lowest losses corresponding of course to the highest total voltage]. Secondly, the discharge losses asymptote to a value of approximately $200 \mathrm{~W} / \mathrm{A}$; this is relatively low and substantially below the target value of $400 \mathrm{~W} / \mathrm{A}$. The breadboard Engine $200 \mathrm{~W} / \mathrm{A}$ value corresponds well to that of the NEXT thruster ( 130 W/A) when adjusted for the $\sim 1.52 \mathrm{X}$ difference in anode surface area.

Plume measurements were obtained for the throttle conditions identified in Table 3. These data are discussed in detail in a companion publication ${ }^{13}$, but are briefly summarized here. A vertically-oriented Faraday probe rake was employed to interrogate the plume structure of the AGI-Engine in order to determine spatial uniformity over a wide range of operating conditions. The rake was designed to pass along horizontal planes through the thruster centerline, discharge cathode centerline, and the plane of the discharge cathode mirrored about the thruster centerline. Data was collected at four axial distances, with the closest approach being $3 \mathrm{~cm}$ from the ion optics. It was determined from this study that the plume of the AGI-Engine is highly-uniform in both the azimuthal and radial directions. Current density variations in the azimuthal direction did not exceed $\pm 5 \%$ at any of the 40 operating conditions tested, with uniformity improving with increasing beam current. Beam flatness ranged from 0.85 to 0.95 , substantially higher than SoA gridded ion thrusters, with flatness also increasing with increasing beam current. Current density profiles are documented in Fig. 10 at closest approach to the ion optics for 3.52 Ampere beam current operation.

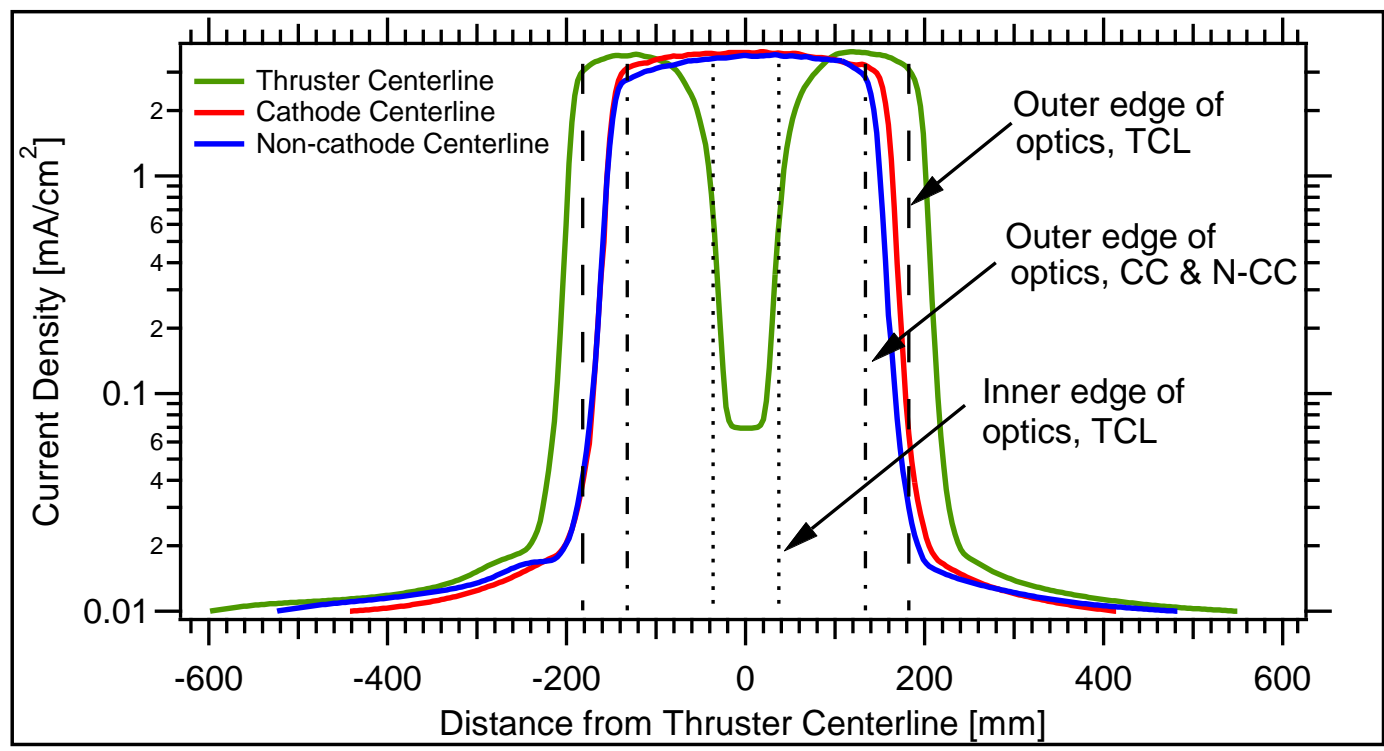

Figure 10 Current Density Measurements vs. Radial Position at $3 \mathrm{~cm}$ Axial Distance and 3.52 Amperes beam current $(\mathrm{TCL}=$ Thruster Centerline, $\mathrm{CC}=$ Cathode Centerline, $\mathrm{N}-\mathrm{CC}=$ Non-Cathode Centerline); Ref. 13

These tests were successful in demonstrating the primary objectives for this hardware; evaluating development tasks \#3 (demonstrating low discharge losses) and \#4 (demonstrating uniform beam current densities). This breadboard AGI-Engine is a test bed with limited capability due to its modest size and (for these tests) sub-optimal ion optics. However the performance of these domed, modified-NEXT ion optics was characterized on the annular discharge chamber, and the overall engine performance was documented.

The perveance of the ion optics were established from analysis of the accelerator grid impingement current vs. total accelerating voltage data (see Fig. 11) over a range of beam currents. The perveance-limited beam current was determined to be:

$$
\mathrm{I}_{\mathrm{b}} \cong 7.96 \times 10^{-5} \cdot\left(\mathrm{V}_{\mathrm{t}-\mathrm{min}}\right)^{3 / 2}
$$

Where $I_{b}$ is the perveance-limited beam current in Amperes, and $V_{t-m i n}$ is the minimum total voltage in volts. Equation 1 compares favorably to that determined for these ion optics operating on a NEXT ion thruster discharge

\footnotetext{
$\S \S$ Operation with simulated beam extraction is accomplished by a reduction in propellant flow rate from that required with beam extraction, biasing the downstream electrode to measure the ion saturation current, and adjusting the saturation current to account for the ion transparency of the ion optics with beam extraction.
} 
when adjusted for the difference in beam areas (the difference associated with the center $8 \mathrm{~cm}$ diameter patch applied for tests on the AGI-Engine discharge).

Performance data for the engine were documented over the throttle conditions identified in Table 3 , and these are presented in Fig. 12, a plot of overall thruster efficiency vs. specific impulse. [Thruster efficiency and Isp were calculated using standard methodology from measured parameters as described in Ref. 14]. The performance data for the breadboard AGI-Engine are consistent with that documented for the standard NEXT thruster throttle table when the efficiency is adjusted for the increase in discharge losses, as expected. The thrust vs. specific impulse for the breadboard is plotted in Fig. 13. Also plotted are the standard NEXT thruster throttle table data. As noted, the AGI-Engine demonstrated higher thrust at lower values of specific impulse. These operating points - below about 3000 seconds Isp and above $50 \mathrm{mN}$ - represent the ETL's identified in Table 3. These extended throttle levels push the 'maximum-thrust envelope' down to lower values of Isp. The breadboard AGI-Engine was operated at a maximum input power of about $6.32 \mathrm{~kW}$, corresponding to about $221 \mathrm{mN}$ thrust.

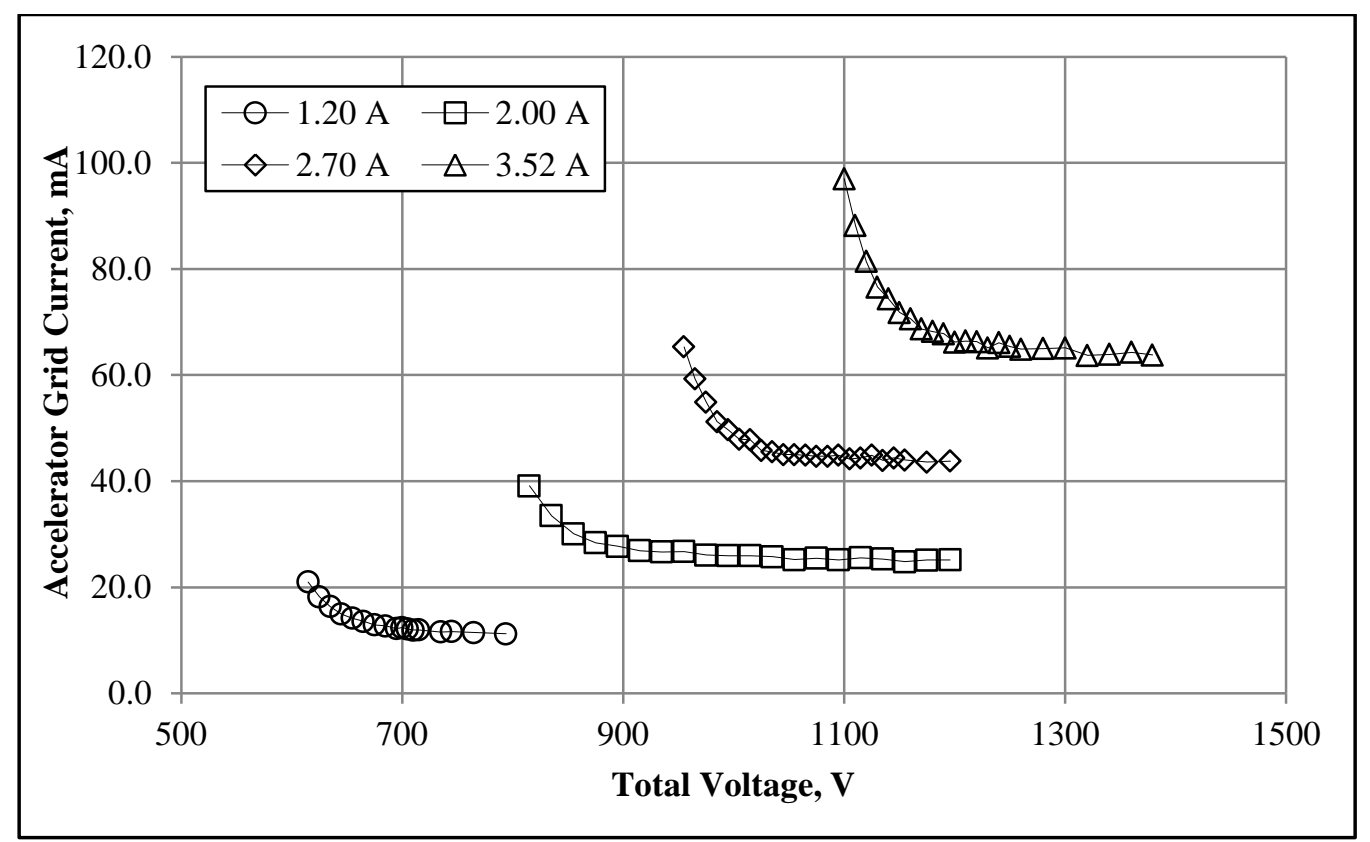

Figure 11 Accelerate Grid Impingement Current vs. Total Accelerating Voltage for a Range of Beam Currents; modified NEXT Ion Optics on Breadboard AGI-Engine

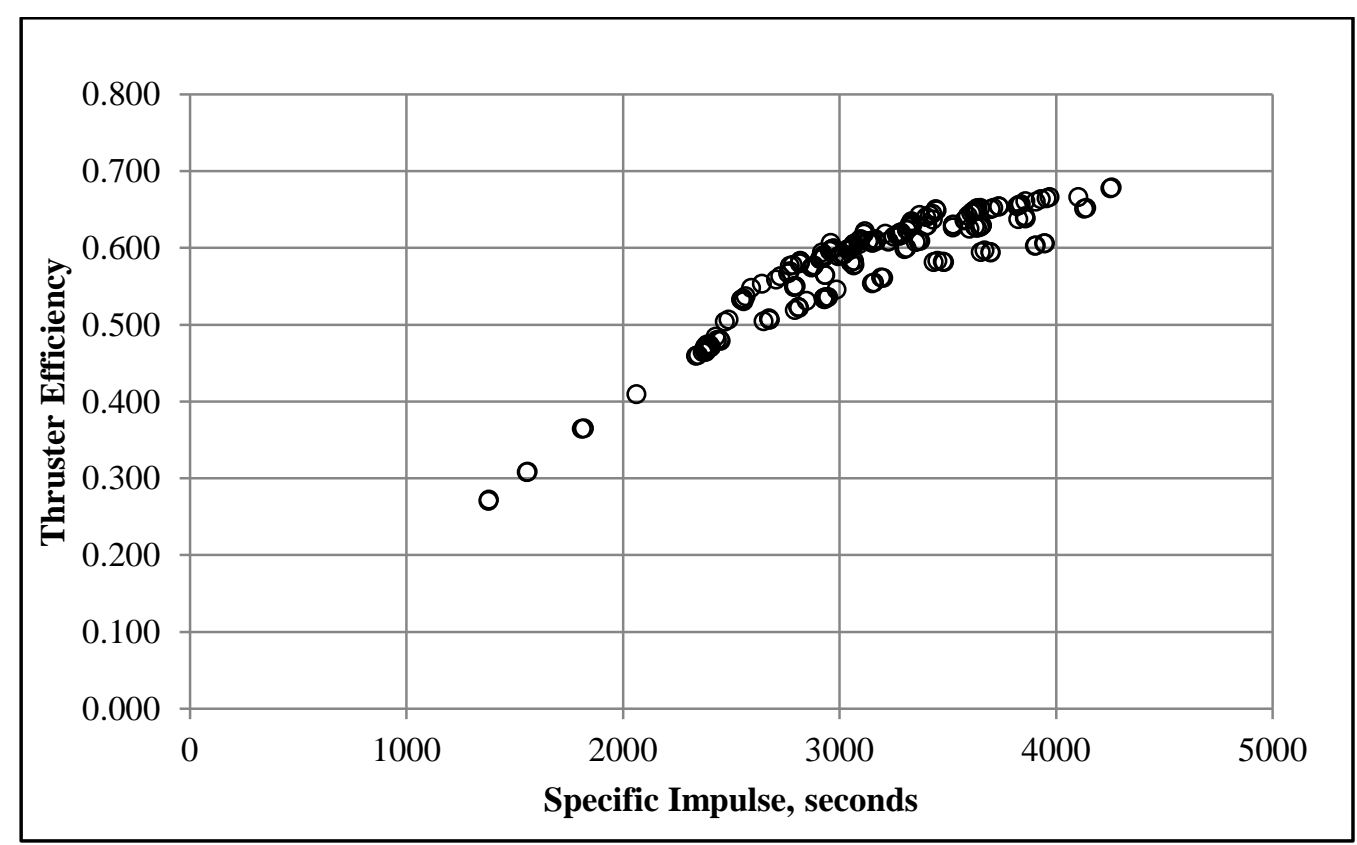

Figure 12 Breadboard AGI-Engine Efficiency vs. Specific Impulse 
Progress demonstrated against the development tasks is identified in Table 4, indicating completion of tasks \#1-\#4. The remaining tasks that will be evaluated with this breadboard engine include: demonstration of annular ion optics at subscale (\#5); demonstration of carbon-based optics (\#9); and evaluating the efficacy of flat electrodes (\#10). These 3 tasks will be addressed with the performance evaluation of annular pyrolytic graphite (PG) flat-geometry ion optics sized for this engine presently under fabrication.

A second much-larger AGI-Engine is presently in design and fabrication. The objectives associated with this hardware will be to address development tasks \#6-\#8: scalability of the annular discharge and optics; demonstrate higher supportable discharge currents than SOA; and demonstrate higher beam current densities than SOA. The engine is sized to yield a beam area and anode area of $>2 \mathrm{X}$ and $>3 \mathrm{X}$ respectively of the NEXT thruster. This 1-Newton Class thrust level engine should have an input power capability up to about $33 \mathrm{~kW}$, with a target of 15-20 $\mathrm{kW}$ at 2700-3300 seconds Isp.

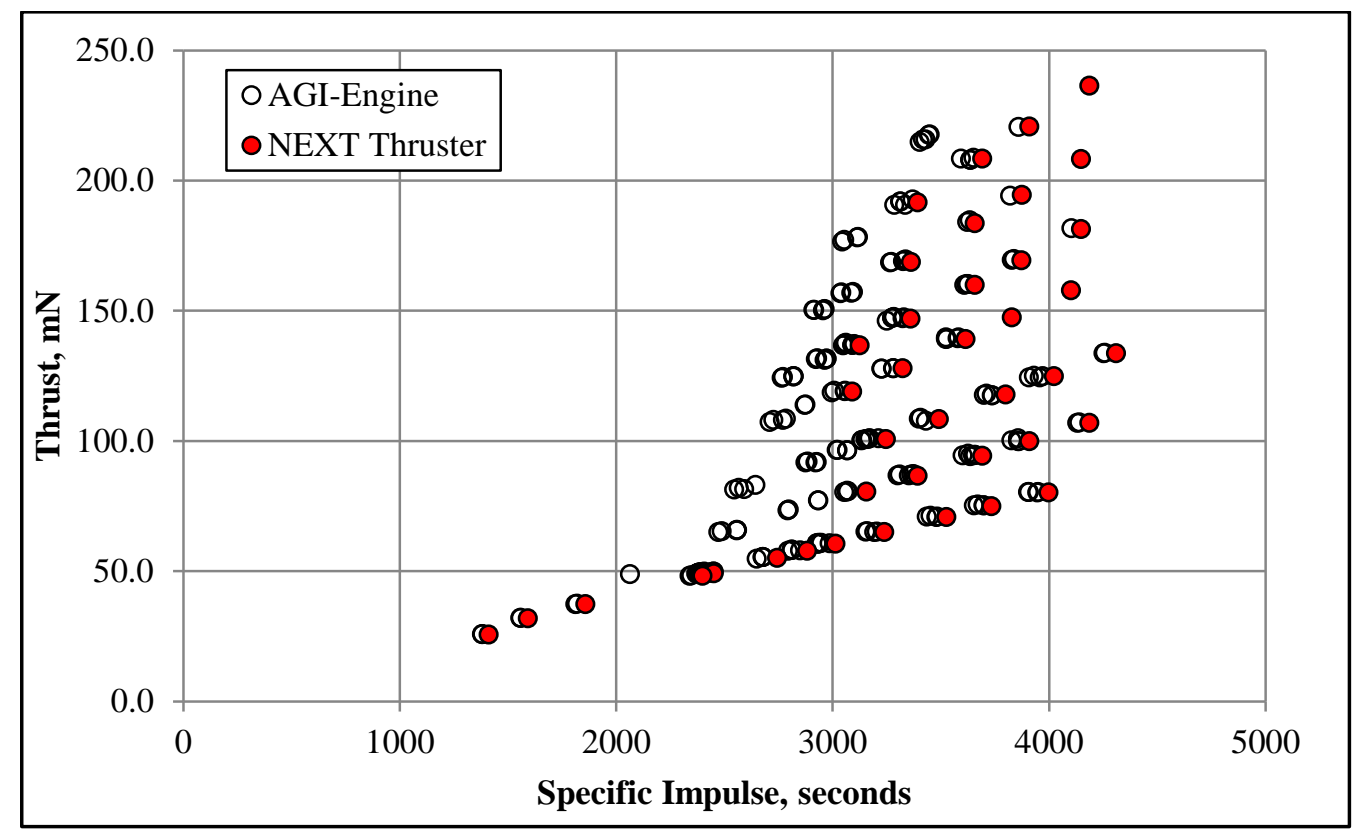

\section{Figure 13 Breadboard AGI-Engine Thrust vs. Specific Impulse; NEXT Throttle Table Data Plotted for Comparison}

Table 4 AGI-Engine Development Task Status and Comment

\begin{tabular}{|c|c|c|}
\hline Development Task & Status & Comment \\
\hline \#1. Demonstrate Stable Annular Discharge Operation & Demonstrated & Breadboard Discharge \\
\hline \#2. Demonstrate Uniform Annular Plasma Densities & Demonstrated & Breadboard Discharge \\
\hline \#3. Demonstrate Low $(<400 \mathrm{~W} / \mathrm{A})$ Discharge Losses & Demonstrated & $\sim 200 \mathrm{~W} / \mathrm{A}$ \\
\hline \#4. Demonstrate Uniform Beam Current Density & Demonstrated & Operation with Beam Extraction \\
\hline $\begin{array}{l}\text { \#5. Demonstrate Feasibility of Annular Ion Optics at } \\
\text { Sub-Scale }\end{array}$ & $\begin{array}{c}\text { To Be } \\
\text { Demonstrated }\end{array}$ & Operation with Beam Extraction \\
\hline $\begin{array}{l}\text { \#6. Demonstrate Scalability of Annular Discharge-and-Ion } \\
\text { Optics }\end{array}$ & $\begin{array}{c}\text { To Be } \\
\text { Demonstrated }\end{array}$ & $>36 \mathrm{~cm}$ Beam Diameter \\
\hline $\begin{array}{l}\text { \#7. Demonstrate Higher Supportable Discharge Currents } \\
\text { than SOA }\end{array}$ & $\begin{array}{c}\text { Partially } \\
\text { Demonstrated }\end{array}$ & $\begin{array}{l}>30 \text { Amperes for } 40 \mathrm{~cm} \varnothing \\
\text { Discharge }\end{array}$ \\
\hline \#8. Demonstrate Higher Beam Current Densities than SOA & $\begin{array}{c}\text { To Be } \\
\text { Demonstrated }\end{array}$ & $>4 \mathrm{~mA} / \mathrm{cm}^{2}$ average \\
\hline \#9. Demonstrate Carbon-Based Annular Ion Optics & $\begin{array}{c}\text { To Be } \\
\text { Demonstrated }\end{array}$ & Pyrolytic Graphite \\
\hline \#10.Demonstrate Feasibility of Flat Annular Ion Optics & $\begin{array}{c}\text { To Be } \\
\text { Demonstrated }\end{array}$ & $\begin{array}{l}\text { Improved Performance \& } \\
\text { Reduced Fabrication Cost }\end{array}$ \\
\hline
\end{tabular}

\section{Conclusion}

A Next-Generation Electric Propulsion Thruster is under development at NASA GRC which has as its design basis an Annular-Geometry Ion Engine. This AGI-Engine is a key to the rapid development of very high-power electric 
thrusters $(>100 \mathrm{~kW}$ ) which have the potential to operate at higher power and thrust densities than SOA thrusters, with increased performance and life times. It does so by providing a pathway to extend the application space of electrostatic ion thruster technology to high power operation at modest levels of specific impulse.

The AGI-Engine could be a stand-alone thruster, or could be configured in a multi-channel geometry with other AGI-Engine discharges, or other EP thrusters such as Hall-Effect thrusters. The latter two configurations could increase the effective dynamic power throttling range, or effective specific impulse range, beyond that achievable by any present alternative EP thruster approach.

A breadboard AGI-Engine discharge was designed, fabricated and tested for purposes of evaluating the efficacy of the concept. The breadboard engine was built from a combination of components originally manufactured for a NEXT $40 \mathrm{~cm}$ ion thruster and those specifically manufactured for the annular engine design. These tests were successful in demonstrating stable annular discharge operation, and uniform annular plasma densities, using a singular discharge hollow cathode with an optimized magnetic circuit. Estimated discharge losses under conditions simulating beam extraction were low and consistent with those values required to yield high overall engine efficiency. The breadboard AGI-Engine was subsequently modified for operation with beam extraction. Tests with beam extraction over a range of throttle levels developed for the NEXT thruster verified both low discharge losses, and a highly-uniform beam current density profile. Optics and overall engine performance were consistent with expectations.

Based on the positive results achieved with the sub-scale breadboard AGI-Engine further evaluation of the concept will be conducted including: test and evaluations of sub-scale flat carbon annular ion optics; and fabrication and test of a larger (1- Newton class) engine to assess concept scalability.

\section{Acknowledgements}

The authors would like to acknowledge the support of GRC's Office of Technology Partnerships and Planning. Funding for this activity was provided through an internal research and development fund sponsored by the Agency's Office of Chief Technologist.

\section{References}

${ }^{1}$ Patterson, M.J., "Next-Generation Electric Propulsion Thrusters," AIAA Paper No. 2011-4812, July 2011.

${ }^{2}$ Patterson, M.J., et al., "Development of an Annular-Geometry Ion Engine," Space Propulsion 2012 Conference Paper 2356236, May 2012.

${ }^{3}$ Dankanich, J.W. and Patterson, M.J., "Benefits of the Annular Gridded-Ion Engine," Space Propulsion 2012 Conference Paper 2377604, May 2012.

${ }^{4}$ Patterson, M.J., Benson, S.W., and Soulas, G. C., "NEXT Ion Propulsion System Development Status," JANNAF Publication SPS-III-14, December 2008.

${ }^{5}$ Hoskins, W.A., et al., "Design of Hall Thrusters for Operation Over a Wide Specific Impulse Range," JANNAF Publication SPS-III-44, December 2008.

${ }^{6}$ Welander, B., et al., "Life and Operating Range Extension of the BPT-4000 Qualification Model Hall Thruster," AIAA No. Paper 2006-5263, July 2006.

${ }^{7}$ Cassady, L.D., et al., "VASIMR Performance Results,” AIAA Paper No. 2010-6772, July 2010.

${ }^{8}$ Polzin, K.A., "Comprehensive Review of Planar Pulsed Inductive Plasma Thruster Research and Technology," Journal of Propulsion and Power, Vol. 27, No. 3, May-June 2011.

${ }^{9}$ Tikhonov, V.B., et al., "Performance of $130 \mathrm{~kW}$ MPD Thruster with an External Magnetic Field and Li as a Propellant," IEPC Paper No. 97-117, October 1997.

${ }^{10}$ Aston, G. and Brophy, J., “A 50-cm Diameter Ion Engine,” AIAA Paper No. 89-2716, July 1989.

${ }^{11}$ Aston, G., Aston, M., and Kolts, J., "Preliminary Tests of Annular Ion Optics," AIAA Paper No. 92-3148, July 1992.

${ }^{12}$ Brophy, J.R., "Simulated Ion Thruster Operation Without Beam Extraction,” AIAA Paper No. 90-2655, July 1990.

${ }^{13}$ Shastry, Patterson, M.J., Herman, D.A., and Foster, J.E., "Current Density Measurements of an Annular-Geometry Ion Engine," to be presented at the $48^{\text {th }}$ AIAA/ASME/SAE/ASEE Joint Propulsion Conference and Exhibit, scheduled for July $30^{\text {th }}-$ August $1^{\text {st }}$ 2012 in Atlanta, Georgia.

${ }^{14}$ Patterson, M.J., "NEXT $\underline{\text { Study of }}$ Thruster Extended Performance (NEXT STEP)”, AIAA Paper No. 2006-4664, July 2006. 